Syndrome: a revised version of the European criteria proposed by the American-European Consensus Group. AnnRheum Dis 2002;61:554-8.

[2] Makula E, Pokorny G, Palkó A.The place of magnetic resonance and ultrasonographic examinations of the parotid gland in the diagnosis and followup of primary Sjögren's syndrome. Rheumatology (Oxford). 2000;39(1):97104.

[3] Niemelä RK, Takalo R, Hakala M. Ultrasonography of salivary glands in primary Sjogren's syndrome. A comparison with magnetic resonance imaging and magnetic resonance sialography of parotid glands. Rheumatology (Oxford). $2004 \mathrm{Jul} ; 43(7): 875-9$.

[4] El Miedany YM, Ahmed I, El Gafaary M. Quantitative ultrasonography and magnetic resonance imaging of the parotid gland: can they replace the histopathologic studies in patients with Sjogren's syndrome? Joint Bone Spine.2004;71(1):29-38.

Disclosure of Interest: None declared

DOI: 10.1136/annrheumdis-2017-eular.5469

\section{AB1069 SHOULDER ULTRASONOGRAPHY IN DIABETIC PATIENTS - IS THERE DAMAGE WITH NO CLINICAL SIGN?}

V.C. Iorgoveanu ${ }^{1}$, V. Bojinca ${ }^{2}$, R. Malitchi ${ }^{2}$, M. Gheorghe $^{2}$, C. Ionescu ${ }^{2}$, R. Ionescu ${ }^{2}{ }^{1}$ Rheumatology, Carol Davila University of Medicine and Pharmacy; ${ }^{2}$ Rheumatology, Saint Mary Clinical Hospital, UMF Carol Davila, Bucharest, Romania

Background: Degenerative lesions in shoulder rises exponentialy with age and diabetes was found to be associated with shoulder pain $[1,2]$.

Objectives: To evaluate the prevalence and type of lesions of shoulder in diabetic patients with no pain using ultrasound (US)

Methods: We included consecutive patients with diabetes with no pain or clinical tumefaction in shoulder. US was performed in both shoulders using the standard scanning planes and dynamic maneuvers. Clinical data as fasting glycemia, BMI, treatment were recorded.

Results: Forty two shoulders were examined in 21 consecutive patients (mean age $67.92+/-7.35$ years, weight $81.75+/-13.57 \mathrm{~kg}$, BMI $25+/-2 \mathrm{~kg} / \mathrm{m}^{2}$, fasting glycemia $151.85+/-33.72 \mathrm{mg} / \mathrm{dl}$ ) with diabetes diagnosis mean 5.33 years $+/-5.99$. Majority of patients were under treatment with oral antidiabetics (58.3\%). Degenerative lesions were found in subscapular (SSc) 33.3\% and supraspinatus (SpS) 8.3\%) tendons as well as intratendinous micro ruptures with calcifications $(33.3 \%$ bilateral calcifications in SSc, SpS). Impingement syndrome was objectified in $16.6 \%$ of examinations. Minimal inflammatory signs as: sub-acromion sub deltoidian bursitis in $50 \%$ (minimum in $33.3 \%, 8.3 \%$ bilateral) and long head biceps tenosynovitis in $58.33 \%$ (8.3\% minimal Doppler signal). $83.3 \%$ showed humeral irregularities and also erosions were found (8.3\%).

Conclusions: Degenerative and minimal inflammatory lesions in shoulder of diabetic patients exist with no clinical sign (pain, tumefaction). Ultrasonography might be an usefull technique to confirm these alterations before the appearance of symptoms.

\section{References:}

[1] Thomas SJ, McDougall C, Brown ID, et al. Prevalence of symptoms and signs of shoulder problems in people with diabetes mellitus. J Shoulder Elbow Surg. 2007:16:748-751.

[2] Abate M, Schiavone C, Salini V. Sonographic evaluation of the shoulder in asymptomatic elderly subjects with diabetes. BMC Musculoskelet Disord. 2010;11:278.

Disclosure of Interest: None declared

DOI: 10.1136/annrheumdis-2017-eular.5482

\section{AB1070 UNRAVELLING AUTOIMMUNE DISEASES THROUGH NAILFOLD CAPILLAROSCOPY}

V.R. Bernardino ${ }^{1,2}$, A.C. Rodrigues ${ }^{1,2}$, A.C. Llado ${ }^{1,2}$, M.A. Fernandes ${ }^{1,2}$, M. Vicente ${ }^{1,2}$, A.C. Grilo ${ }^{2,3}$, A. Panarra ${ }^{1,2}$, M.F. Moraes-Fontes ${ }^{1,2} \cdot{ }^{1}$ Unidade de Doenças Auto-imunes/Medicina 7.2, Hospital de Curry Cabral, Centro Hospitalar de Lisboa Central; ${ }^{2}$ NEDAI/SPMI - Núcleo de Estudos de Doenças Autoimunes, Sociedade Portuguesa de Medicina Interna, Lisbon; ${ }^{3}$ Serviço de Medicina Interna, Hospital Beatriz Ângelo, Loures, Portugal

Background: Nailfold capillaroscopy (NC) is non-invasive and used by clinicians as a diagnostic tool. It allows the distinction between primary and secondary Raynaud Phenomenon (RP), the latter usually associated to autoimmune diseases (AID).

Objectives: Characterize the utility of NC assessment for diagnosis of AID and to evaluate main differences in NC pattern, according to the presence of RP. Methods: NC were performed with a Videocap biomicroscope using well established classification criteria [1]. NC images and reports from all patients evaluated from January 2011 to final December 2016 were retrospectively analysed. Comparisons were made using the Wilcoxon Rank Sum and Chi square tests, $p$ values of $<0,05$ were considered statistically significant.

Results: In the last 6 years, 1100 NC were performed, 159 to man and 941 to women. Mean age was $42[ \pm 19]$ years. NC requests came from 17 different hospital units. RP was present in $83 \%$ of patients $(\mathrm{RP}+, \mathrm{n}=909)$ of whom $71 \%$ $(n=641)$ had a prior diagnosis of AID, most frequently Systemic Sclerosis (SSc)
(24\%, $n=143$ ), Systemic Lupus Erythematosus (SLE) $(21 \%, n=123)$, Sjögren's Syndrome (SS) $(10 \%, n=62)$, Mixed Connective Tissue Disease (MCTD) $(9 \%$, $n=52)$ and Antiphospholipid Syndrome (APS) $(8 \%, n=48)$. NC patterns allowed for the classification of RP+ subjects into primary $(3 \%)$ and secondary $(81 \%)$; in $4 \%$ of subjects NC findings were abnormal but inconclusive. From secondary RP, scleroderma $(37 \%)$ and non-scleroderma pattern $(62 \%)$ were further separated; the former was later classified according to scleroderma-like $(15,02 \%)$, early $(33 \%)$, active $(38 \%)$ and late $(15 \%)$ scleroderma patterns.29\% of RP+ patients did not have AID diagnosed; NC disclosed the diagnosis of SSc $(n=24)$, APS $(n=5)$, SS $(n=4)$, SLE $(n=2)$, MCTD $(n=1)$, overlapping syndrome $(n=1)$ and paraneoplastic syndrome $(n=1)$.

In RP- patients, the main diagnosed AID were SLE (20\%, $n=17)$, SSc (14\%, $n=12)$ and SS $(8 \%, n=7)$. NC results in RP- subjects were normal (24\%) (including $92 \%$ of controls), inconclusive (22\%) and suggestive of capillaritis (16\%). Although RP-, some patients $(38 \%)$ presented dysmorphic capillaries suggestive of secondary involvement (38\%); NC findings in these patients included megacapillaries and microhemorrhages (scleroderma-like $(26 \%)$, early $(41 \%)$, active $(30 \%)$ and late $(7 \%))$.

Demographic data was similar in both groups. Statistically significantly higher frequencies of AID $(p<0.0001)$, SSc $(p=0.0006)$, NC secondary non-SSc pattern $(p<0.0001)$ and NC secondary active SSc pattern $(p=0.002)$ were found in RP+ patients.

Conclusions: $\mathrm{NC}$ findings in RP+ were more pathological than in RP-subjects, probably due to pre-existing AID and more frequent positivity. Secondary non scleroderma pattern was more prevalent in RP+ patients. In RP- group, almost a quarter of NC assessments were normal, but capillary abnormalities were also revealed, suggesting this diagnostic approach can help to disclosure microvascular disease, even if RP is absent. NC further disclosed important leads to diagnose SSc, APS and MCTD in our population.

References:

[1] Cutolo M et al. Arthritis and Rheumatism. 2003 Nov; 48(11):3023-3030.

Disclosure of Interest: None declared

DOI: 10.1136/annrheumdis-2017-eular.1242

\section{AB1071 SIMPLIFIED ASSESSMENT IN NAILFOLD CAPILLAROSCOPY IN RHEUMATOLOGY}

V. Durigan, G. Calizaya, A. Secco, F.E. Romanini, M.L. Sormani de Fonseca, V. Ortiz, M. Uemura, L. Takashima, M. Mamani. Rivadavia, CABA, Argentina

Background: Nailfold Capillaroscopy is a non-invasive diagnostic technique designed to evaluate small vessels of the microcirculation. The most important indication for capillaroscopy is Raynaud's phenomenon. The complexity and meticulous evaluation of the eight fingers is difficult to apply in daily practice given the limited availability of time to perform. For this reason it is necessary to develop simple and abbreviated techniques, to achieve an optimal and rapid evaluation of the patient.

Objectives: Determine the performance of the method of the $4^{\circ}$ finger for the diagnosis of SD pattern in patients with Raynaud's Phenomenon taking the eight finger pattern as a gold standard.

Methods: Cross-sectional study with blinded and independent measurements. Nailfold Capillaroscopy was performed on the four fingers of each hand, except thumbs. Another observer evaluated the 4 th finger of the hands. The interobserver agreement was made before carrying out the study and was $100 \%$. The 8 -finger method (gold standard) was considered positive when at least one finger has SD pattern and the $4^{\circ}$ finger method was considered positive when at least one of them presents the SD pattern. We included patients older than 18 years with a diagnosis of Raynaud Phenomenon. Patients with thickening of the skin in the nailfold, digital lesion that made it difficult to assess (trauma, amputation, burns, etc.) and patients who did not consent to the procedure were excluded.

Results: We included 78 patients, $90 \%$ was female. The mean age was 53 years (DS +/- 13.5). Sixty-three patients had a score of eight fingers positive (cases) and 15 had a score of eight fingers negative (controls). The sensitivity of the $4^{\circ}$ finger evaluation method was $89 \%(95 \% \mathrm{Cl}: 82-96 \%)$ and $93 \%$ specificity $(95 \%$ $\mathrm{Cl}: 88-99 \%)$. The positive predictive value of this method was $98 \%(95 \% \mathrm{Cl}$ : $95-100 \%)$ and the negative predictive value was $67 \%(95 \% \mathrm{Cl}: 56-77 \%)$. The positive likelihood ratio was $13(95 \% \mathrm{Cl}$ : 2-89).

Conclusions: The simplified method of the $4^{\circ}$ finger showed good performance for the diagnosis of SD pattern compared to the standard method of evaluation of the 8 fingers.

References:

[1] Sormani de Fonseca ML. Manual de Capilaroscopía. Buenos Aires: McDowell, 2000. Capítulo 1: 35.

[2] Cutolo M, Sulli A, Pizzorni C, Accordo S. Nailfold videocapillaroscopic assessment of microvascular damage in systemic sclerosis. J Rheumatol 2000; $27: 155-60$

[3] M. Cutolo et al. Nailfold videocapillaroscopic patterns and serum autoantibodies in systemic sclerosis. Rheumatology 2004; 43: 719-726.

[4] Ariane L. Herrick, Maurizio Cutolo. Clinical Implications From Capillaroscopic Analysis in Patients With Raynaud's Phenomenon and Systemic Sclerosis. Arthritis And Rheumatism 2010. Vol 62, No 9: 2595-2604.

[5] Sonsoles Piera -Velázquez et al. Patogénesis de la Esclerosis Sistémica. Rev Peruana de Reumatología 2004; 10(3): 34-42. 